\title{
Oxygen Equilibrium of Hemoglobin E
}

\author{
H. Franklin Bunn, W. Delano Meriwether, Stanley P. Balcerzak, and \\ Donald L. RuCKNagel
}

From the Thorndike Memorial Laboratory, Harvard Medical Service, Boston

City Hospital, Boston 02118 and the Harvard Medical School, Boston, Massachusetts 02115; the Department of Medicine, Ohio State University, Columbus, Ohio 43210; and the Department of Human Genetics, University of Michigan School of Medicine, Ann Arbor, Michigan 48105

\begin{abstract}
A в S T R A C T Oxygen equilibrium was determined on hemoglobin of individuals both heterozygous and homozygous for hemoglobin $\mathrm{E}$. The whole blood oxyhemoglobin dissociation curve of $\mathrm{AE}$ blood was identical to that of normal AA blood. E hemoglobin, isolated by diethylaminoethyl Sephadex and carboxymethyl cellulose column chromatography, had oxygen affinity, hemeheme interaction, and Bohr effect identical to those of hemoglobin A prepared from the same column. Furthermore, the two hemoglobins had equal reactivity with 2,3-diphosphoglycerate. Phosphate-free hemolysates of blood from $\mathrm{E}$ and $\mathrm{A}$ homozygotes also had identical oxygen saturation curves. These results do not confirm earlier reports that hemoglobin $\mathrm{E}$ has an abnormally low oxygen affinity.
\end{abstract}

\section{INTRODUCTION}

Functional studies of certain abnormal human hemoglobins have provided valuable information on the mechanism by which ligands, such as oxygen, bind to hemoglobin. Most hemoglobin variants having increased oxygen affinity have amino acid substitutions in regions of the molecule which are considered vital to its function (1). Several recent reviews have listed hemoglobin E $\left(\alpha_{2} \beta_{2}{ }^{28}{ }^{14} \rightarrow{ }^{15 s}\right)$ among the hemoglobin variants that have abnormally low oxygen affinity (2-4). Supporting experimental evidence, however, is somewhat circumstantial (5-8). A more detailed examination of the oxygen equilibrium of hemoglobin $\mathrm{E}$ is warranted not only because of structural-functional implications but also because this hemoglobin is the third most common variant world-wide, and any significant alteration of its oxygen affinity could have important clinical implications.

Received for publication 6 July 1972 and in revised form 14 August 1972.

\section{METHODS}

Blood was obtained from a 32 -yr old Thai male homozygous for hemoglobin $\mathrm{E}$. His hemoglobin concentration was 15.6 $\mathrm{g} / 100 \mathrm{ml}$; hematocrit was $44.2 \%$. Slight anisocytosis, poikilocytosis, and many target cells were noted on the stained peripheral blood film. Cellulose acetate electrophoresis showed only hemoglobin $\mathrm{E}$ as the major component. Hemoglobin $\mathrm{F}$ comprised $0.9 \%$ of the total as measured by alkali denaturation. A sample of this individual's blood was airmailed in acid citrate dextrose and on ice for oxygen equilibrium measurements. Blood was also obtained from an American Black male heterozygous for hemoglobin $\mathrm{E}$. The structure of the $E$ hemoglobin from each donor was verified by two-dimensional peptide mapping (9) of the variant polypeptide chains isolated by the column chromatographic method of Clegg, Naughton, and Weatherall (10). The abnormal tryptic peptides were eluted from the paper chromatogram and the composition verified on a Beckman Automatic Amino Acid Analyser 120C (Beckman Instruments, Inc., Palo Alto, Calif.).

Phosphate-free hemoglobin solutions and a standard solution of 2,3-diphosphoglycerate $(2,3-D P G)^{1}$ were prepared as described previously (11). From a hemolysate of the heterozygote, $\mathrm{A}$ and $\mathrm{E}$ hemoglobins were separated by two types of ion exchange chromatography: diethylaminoethyl Sephadex (DEAE-Sephadex) (12) and carboxymethyl cellulose (CM-cellulose) (13). Hemoglobin E migrates more rapidly than $\mathrm{A}$ on DEAE-Sephadex. On C.M-cellulose, the reverse is true. Hemoglobin E comprised about $35 \%$ of the total. Auto-oxidation of hemoglobins on the CM-cellulose column was prevented by equilibrating the column and eluting buffer with 1 atm of carbon monoxide. Carboxyhemoglobin was converted to oxyhemoglobin as described previously (11). The hemoglobin-rich peaks that were eluted from the columns were concentrated by ultrafiltration with a Diaflo membrane. ${ }^{2}$ There was no carboxyhemoglobin and less than $5 \%$ methemoglobin detectable on completion of the oxygen equilibrium measurements.

Whole blood oxygen equilibria were done on fresh hepa-

\footnotetext{
${ }^{1}$ Abbreviations used in this paper: 2,3-DPG, 2,3-diphosphoglycerate; CM-cellulose, carboxymethyl cellulose; DEAESephadex, diethylaminoethyl Sephadex.

${ }^{2}$ Amicon Corp., Lexington, Mass.
}

2984 The Journal of Clinical Investigation Volume 51 November 1972 
rinized specimens of $\mathrm{AE}$ and $\mathrm{AA}$ blood. 2.5- $\mathrm{ml}$ specimens were mixed in a rotating tonometer at $37^{\circ} \mathrm{C}$ with hydrated gas mixtures consisting of known amounts of oxygen, $5 \%$ carbon dioxide, and balance nitrogen. 10-min incubation periods were sufficient to insure full equilibration. On each specimen, the oxyhemoglobin and total hemoglobin contents were measured by a CO oximeter. ${ }^{8}$ The instrument was standardized with blood treated with sodium dithionite $\left(0 \% \mathrm{O}_{2}\right.$ saturation) and pure oxygen gas $\left(100 \% \mathrm{O}_{2}\right.$ saturation). $\mathrm{pH}$ was measured anaerobically at $37^{\circ} \mathrm{C} .^{1}$ The $\mathrm{pO}_{2}$ was corrected to a standard plasma $\mathrm{pH}$ of 7.40 by the use of the following Bohr factor: $\Delta \log \mathrm{pO}_{2} / \Delta \mathrm{pH}=-0.48$. Spectrophotometric oxygen equilibrium curves were done at $20^{\circ} \mathrm{C}$ on $0.1 \mathrm{~mm}$ (tetramer) hemoglobin solution in $0.05 \mathrm{M}$ bis-Tris ${ }^{4}$ or Tris buffer, $\mathrm{pH}$ 6.4-8.6 and sufficient $\mathrm{NaCl}$ so that the chloride ion concentration was $0.10 \mathrm{M}$ (11). Red cell 2,3-DPG was measured by the method of Keitt (14).

\section{RESULTS}

Whole blood oxygen saturation curves done simultaneously on AA and AE individuals are shown in Fig. 1. The two blood specimens had identical and normal oxygen affinities. Furthermore, each had normal red cell 2,3DPG: AE, 4.68 mmoles/liter RBC; AA, 4.40 mmoles/ liter RBC. Normal mean $\pm 1 \mathrm{SD}=4.5 \pm 0.4 \mathrm{~mm}$.

The oxygen affinities and $n$ values of $\mathrm{E}$ and $\mathrm{A}$ hemoglobins isolated on the same columns are shown in Fig. 2. The type of ion exchange resin and, secondarily,

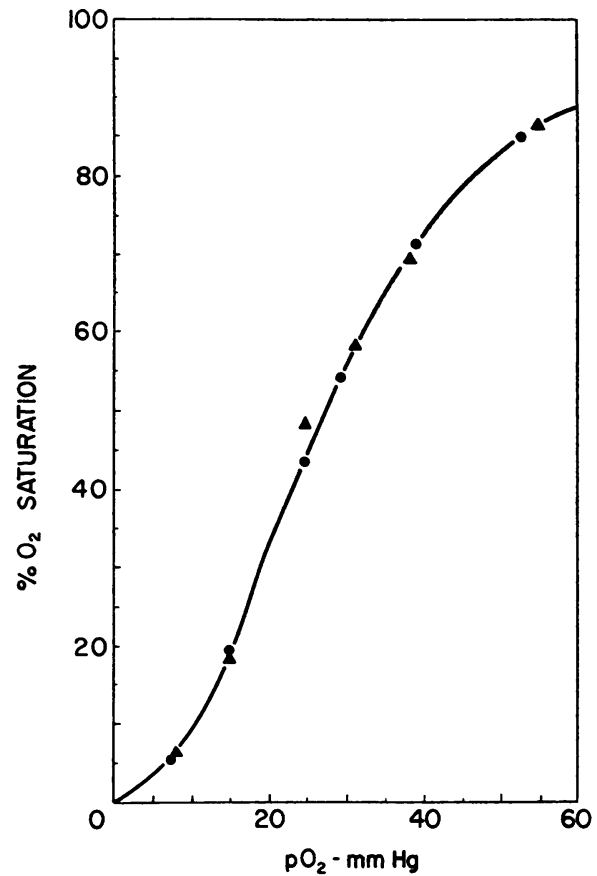

Figure 1 Whole blood oxygen equilibria, $\mathrm{pH} 7.40,37^{\circ} \mathrm{C}$. $\boldsymbol{\Lambda}$, AE heterozygote. $\bullet$, normal (AA homozygote).

${ }^{3}$ Instrumentation Laboratories, Inc., Lexington, Mass.

"General Biochemicals Div., Chagrin Falls, Ohio.
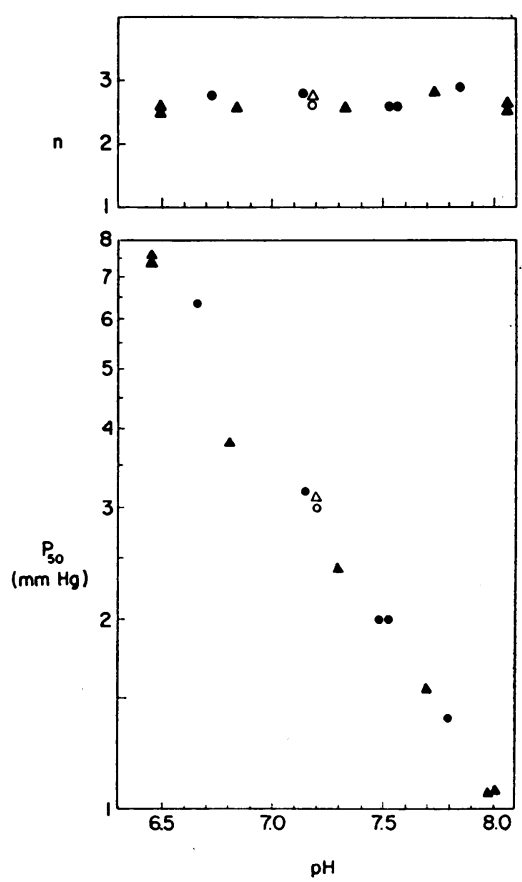

Figure 2 Alkaline Bohr effect of isolated $\mathrm{A}$ and $\mathrm{E}$ hemoglobins. Below: $P_{50}$ is plotted on a logarithmic scale against pH. $0.1 \mathrm{~mm}$ hemoglobin in $0.1 \mathrm{~m}$ chloride, $0.05 \mathrm{M}$ Tris or bis-Tris buffer, $20^{\circ} \mathrm{C}$. Above: Hill's $n$ is plotted against $\mathrm{pH}$. , hemoglobin A prepared on DEAE-Sephadex; $O$, hemoglobin A prepared on CM- cellulose; $A$, hemoglobin $E$ prepared on DEAE-Sephadex; $\triangle$, hemoglobin $E$ prepared on CM-cellulose.

the length of time the hemoglobins remained on the column had no significant effect on their oxygen equilibria. Over a wide $\mathrm{pH}$ range, the two hemoglobins had nearly identical values for $P_{50}$, the partial pressure at which the hemoglobin solutions were half-saturated. Furthermore, $\mathrm{A}$ and $\mathrm{E}$ hemoglobins had the same degree of heme-heme interaction (subunit cooperativity). The calculated alkaline Bohr factor $\left(\Delta \log P_{50} / \Delta \mathrm{pH}\right)$ for the two hemoglobins was -0.54 , in good agreement with a value of -0.57 obtained in this laboratory for normal phosphatefree human hemolysate. Hemoglobins $\mathrm{A}$ and $\mathrm{E}$ showed identical reactivity to $0.2 \mathrm{~mm}$ 2,3-DPG (Table I). Identical oxygen equilibria were obtained on phosphatefree hemolysates prepared from blood specimens of homozygotes for hemoglobins $\mathrm{A}$ and $\mathrm{E}$ (Table I).

\section{DISCUSSION}

These data indicate that hemoglobin $E$ has oxygen equilibria identical to that of hemoglobin A. This contrasts with the results of Thompson, Warrington, and Bell (5) who studied A and E hemoglobins isolated from the blood of an $\mathrm{AE}$ heterozygote. The single pair of oxygen dissociation curves which they reported, 
TABLE I

Oxygen Equilibria of $A$ and E Hemoglobins*

\begin{tabular}{|c|c|c|c|c|c|}
\hline \multirow[b]{2}{*}{ Experiment } & \multirow[b]{2}{*}{ 2,3-DPG } & \multicolumn{2}{|c|}{ A } & \multicolumn{2}{|c|}{$\mathrm{E}$} \\
\hline & & $P_{50}$ & $n \ddagger$ & $P_{50}$ & $n \ddagger$ \\
\hline \multirow{4}{*}{$I \S$} & $m \mathrm{M}$ & $m m \mathrm{Hg}$ & & $m m H g$ & \\
\hline & 0 & 3.7 & 2.9 & 3.9 & 2.7 \\
\hline & & 3.9 & 2.9 & 3.9 & 2.9 \\
\hline & 0.2 & 7.0 & 2.9 & 7.4 & 2.6 \\
\hline \multirow[t]{2}{*}{ II $\|$} & 0 & 3.0 & 2.7 & 3.1 & 2.7 \\
\hline & 0.2 & 6.6 & 2.7 & 6.8 & 2.7 \\
\hline
\end{tabular}

* $0.1 \mathrm{~mm}$ hemoglobin (tetramer) in $0.1 \mathrm{M} \mathrm{NaCl}, 0.05 \mathrm{M}$ bis-Tris buffer, $\mathrm{pH} 7.20,20^{\circ} \mathrm{C}$.

$\ddagger n$ is the coefficient in the Hill equation: $(Y /[1-Y])$ $=\left(p \mathrm{O}_{2} / \mathrm{P}_{\mathbf{3} 0}\right)^{n}$, where $Y$ is fractional saturation of hemoglobin with oxygen. $n$ is a measure of subunit cooperativity.

$\S$ Phosphate-free hemolysates prepared from the blood of homozygotes.

$\|$ Hemoglobins purified by chromatography on DEAESephadex.

showed the oxygen affinity of hemoglobin $\mathrm{E}$ to be $11 \%$ lower than that of hemoglobin A. However, a Hill plot of these data reveals abnormally low $n$ values of 2.0 for each specimen, indicating impairment of heme-heme interaction. It is likely that denaturation and/or auto-oxidation had occurred, making any small difference in oxygen affinity somewhat dubious.

Bellingham and Huehns $(7,8)$ measured oxygen dissociation of hemoglobin of intact red cells suspended in isotonic phosphate buffer. They found that an individual homozygous for hemoglobin $\mathrm{E}$ with $5 \%$ hemoglobin $\mathrm{F}$ had a $P_{50}$ of $40.5 \mathrm{~mm} \mathrm{Hg}$ compared with a normal range of 30-32 mm Hg $(7,8)$. Kolatat (6) also found a similar "shift to the right" in two E homozygotes. Furthermore Bellingham and Huehns (8), observed decreased red cell oxygen affinity in two patients with E- $\beta$-thalassemia. These studies were completed before the importance of red cell 2,3-DPG on oxygen binding was appreciated. The low oxygen affinity may have been due in part to increased red cell 2,3-DPG particularly if the mean age of the red cells was subnormal (15). These patients had varying degrees of anemia. Bellingham and Huehns suggested that incomplete compensation of hemolysis, i.e. "anemia," was due in part to the right shift in the oxygen dissociation curve allowing enhanced delivery of oxygen to tissue. However, this is not a universal phenomenon in hemoglobin $\mathrm{E}$ disease since homozygotes, including the one studied here, have been reported who have normal hemoglobin levels and packed cell volumes (16).

It is possible that oxygen affinity of hemoglobin $\mathrm{E}$ becomes abnormally low if it is in concentrated solution.
This would be true if the deoxy-conformation of hemoglobin $\mathrm{E}$ were stabilized by aggregation in a manner similar to deoxyhemoglobin S (17). Unfortunately, we were not able to do a whole blood oxygen saturation curve on a fresh specimen from an $\mathrm{E}$ homozygote. However, as shown in Fig. 1, the whole blood oxygen affinity of an $\mathrm{AE}$ heterozygote was normal..$^{5}$ It is noteworthy that the functionally abnormal human hemoglobin variants which have been reported to date have all appeared in heterozygotes having abnormal whole blood oxyhemoglobin dissociation curves.

Morimoto, Lehmann, and Perutz (4) suggested that the amino acid substitution in hemoglobin $\mathrm{E}$ might destabilize the oxy-conformation leading to decreased oxygen affinity. However, if this were true, low oxygen affinity should be at least as apparent in a dilute hemoglobin solution as in a concentrated one.

\section{ACKNOWLEDGMENTS}

The technical assistance of Miss Allison Chao and Miss Margaret McDonough is greatly appreciated. We thank Dr. E. R. Huehns for providing additional information cited in this report.

This work was supported in part by National Institute of Health Grants AM05391, HE07652, NHLI-71-2107-B, GM-15419, and RR76 and by Contract DADA17-70-C-0043 from the U. S. Army Medical Research and Development Command.

\section{REFERENCES}

1. Perutz, M. F. 1970. Stereochemistry of cooperative effects in hemoglobin. Nature (Lond.). 228: 726.

2. Perutz, M. F., and H. Lehmann. 1968. Molecular pathology of human haemoglobin. Nature (Lond.). 219: 902.

3. Stamatoyannopoulos, G., A. J. Bellingham, C. Lenfant, and C. A. Finch. 1971. Abnormal hemoglobins with high and low oxygen affinity. Annu. Rev. Med. 22 : 221.

4. Morimoto, H., H. Lehmann, and M. F. Perutz. 1971. Molecular pathology of human haemoglobin: stereochemical interpretation of abnormal oxygen affinities. Nature (Lond.). 232 : 408.

5. Thompson, R. B., R. L. Warrington, and W. N. Bell. 1965. Physiologic differences in hemoglobin variants. Am. J. Physiol. 268: 198.

6. Kolatat, T. 1964. Oxygen affinity of hemoglobin E. Siriraj Hosp. Gaz. 16 : 205.

7. Bellingham, A. J., and E. R. Huehns. 1968. Compensation in haemolytic anemias caused by abnormal haemoglobins. Nature (Lond.) 218: 924.

8. Bellingham, A. J., and E. R. Huehns. 1969. Oxygen dissociation in red cells from patients with abnormal hemoglobins and pyruvate kinase deficiency. Försvarsmedicin. 5 : 209.

\footnotetext{
${ }^{5}$ Huehns has also found that the red cell oxygen binding curve was normal in an $\mathrm{AE}$ heterozygote, and that hemoglobin $\mathrm{E}$ in dilute solution had the same oxygen affinity and 2,3-DPG reactivity as hemoglobin A. (E. R. Huehns, personal communication.)
} 
9. Chernoff, A. I., and J. C. Liu. 1961. The amino acid composition of hemoglobin II. Analytical techniques. Blood J. Hematol. 17 : 54.

10. Clegg, J. B., M. A. Naughton, and D. J. Weatherall. 1968. Separation of $\alpha$ - and $\beta$-chains of human haemoglobin. Nature (Lond.). 219: 69.

11. Bunn, H. F., and R. W. Briehl. 1970. The interaction of 2,3-diphosphoglycerate with various human hemoglobins. J. Clin. Invest. 49 : 1088.

12. Huisman, T. H. J., and A. M. Dozy. 1965. Studies on the heterogeneity of hemoglobin. IX. The use of tris (hydroxymethyl) aminoethane $\mathrm{HCl}$ buffers in the anion exchange chromatography of hemoglobins. J. Chromatogr. $19: 160$.

13. Charache, S., D. J. Weatherall, and J. B. Clegg. 1966.
Polycythemia associated with a hemoglobinopathy. $J$. Clin. Invest. $45: 813$.

14. Keitt, A. S. 1971. Reduced nicotinamide adenine dinucleotide-linked analysis of 2,3-diphosphoglyceric acid: spectrophotometric and fluorometric procedures. J. Lab. Clin. Med. $77: 470$.

15. Bunn, H. F., and J. H. Jand1. 1970. Control of hemoglobin function within the red cell. N. Engl. J. Med. 282: 1414.

16. Lehmann, H., P. Story, and H. Thien. 1956. Haemoglobin $\mathrm{E}$ in Burmese. Br. Med. J. 1 : 544.

17. May, A., and E. R. Huehns. 1972. The mechanism of the low oxygen affinity of red cells in sickle cell disease. Blut. Z. Gesamte Blutforsch. (Suppl. Haematologie und Bluttranfusion) $10: 279$. 